\title{
Resposta produtiva do meloeiro sob diferentes lâminas de água e doses de nitrogênio
}

\section{Productive response of melon under different water depths and nitrogen levels}

\author{
Agenor Francisco ROCHA JUNIOR ${ }^{1}$; Francisco Edinaldo Pinto MOUSINHO ${ }^{2}$; \\ Cristiana Araujo SOARES ${ }^{3}$; Edilson Ramos GOMES ${ }^{4}$; Marcos Emanuel da Costa VELOSO ${ }^{5}$; \\ Adeodato Ari Cavalcante SALVIANO ${ }^{6}$
}

${ }^{1}$ Eng. Agr. Msc em Agronomia (Produção Vegetal); Universidade Federal do Piauí-UFPI; agenorrochabsbpi@hotmail.com ${ }^{2}$ Eng. Agr. Prof. Dr.; Universidade Federal do Piauí-UFPI; edinaldomousinho@yahoo.com.br

${ }^{3}$ Autor para correspondência; Doutoranda em Agronomia (Irrigação e Drenagem), Faculdade de Ciências Agronômicas FCA/UNESP; Departamento de Engenharia Rural; Fazenda Experimental Lageado, Rua Doutor José Barbosa de Barros, no 1780, CEP: 18610-307, Botucatu-SP; criwan_1@hotmail.com

${ }^{4}$ Doutorando em Agronomia (Irrigação e Drenagem), Faculdade de Ciências Agronômicas - FCA/UNESP; edilsonevj@hotmail.com

${ }^{5}$ Eng. Agr. Pesquisador Dr.; Embrapa Meio-Norte (Irrigação e Drenagem); marcos.emanuel@embrapa.br

${ }^{6}$ Eng. Agr. Prof. Dr.; Universidade Federal do Piauí-UFPI; asalvian@uol.com.br

Recebido em: 18-04-2015; Aceito em: 26-10-2015

\section{Resumo}

Embora o Estado do Piauí possua boas condições edafoclimáticas para o cultivo do meloeiro, ainda são poucas as informações técnicas e científicas da correta quantidade de água e de adubação nitrogenada para a cultura do melão que, por sua vez, representem melhor retorno econômico. Diante disto, o objetivo do presente trabalho foi avaliar a resposta produtiva do meloeiro a aplicação de diferentes lâminas de água e de adubação nitrogenada nas condições edafoclimáticas de Teresina, Piauí. O delineamento estatístico foi o de blocos ao acaso, com parcelas subdivididas e quatro blocos, sendo que as parcelas tinham cinco níveis de irrigação (L1, L2, L3, L4 e L5), correspondendo a 0,35; 0,7; 1,0; 1,5 e 2,0 vezes a evapotranspiração da cultura (ETc), respectivamente, e as subparcelas continham quatro doses de nitrogênio (N0, N1, N2 e N3), correspondentes a 0; 75; 150 e $300 \mathrm{~kg} \mathrm{ha}^{-1}$ de N, respectivamente. Utilizou-se do híbrido de meloeiro "Goldex", plantado no espaçamento de 2,0 m entre linhas e 0,25 m entre plantas. Verificou-se que os fatores água e nitrogênio apresentam efeito significativo sobre a produtividade do melão, enquanto a interação entre os fatores não é significativa. A máxima produtividade estimada foi de $28.752,3 \mathrm{~kg} \mathrm{ha}^{-1}$, obtido com a aplicação de $675 \mathrm{~mm}$ de água e $199,1 \mathrm{~kg} \mathrm{ha}^{-1}$ de nitrogênio. Já a máxima receita líquida estimada ( $\left.R \$ 4.247,60\right)$ foi obtida com nível de produtividade de $28.517,50 \mathrm{~kg} \mathrm{ha}^{-1}$, aplicando $597,1 \mathrm{~mm}$ de água e $198,3 \mathrm{~kg} \mathrm{ha}^{-1} \mathrm{de} \mathrm{N}$.

Palavras-chave adicionais: Cucumis melo L.; evapotranspiração; irrigação localizada.

\begin{abstract}
Although the Piauí State has good soil and climatic conditions for the cultivation of melon, there are few technical and scientific information of the correct amount of water and nitrogen fertilizer for melon crop which represents better return economic. Thus, this study evaluated the response of the production in melon after application of different depths of water and nitrogen fertilizer on the soil and climate conditions of Teresina, Piauí State. The statistical design was a randomized blocks design with split plots and four blocks. The parcels were five levels of irrigation (L1, L2, L3, L4 and L5), corresponding to $0.35 ; 0.7 ; 1.0 ; 1.5$ and 2.0 times crop evapotranspiration (ETc), respectively. The subplots contained four nitrogen levels (N0, N1, N2 and N3), corresponding to $0,75,150$ and $300 \mathrm{~kg} \mathrm{ha}^{-1} \mathrm{~N}$, respectively. We used the melon hybrid "Goldex", planted in a row spacing of $2.0 \mathrm{~m}$ between row and $0.25 \mathrm{~m}$ between plants. We found that water and nitrogen factors have a significant effect on productivity melon, while the interaction between the factors is no significative. The estimated maximum productivity was $28752.3 \mathrm{~kg} \mathrm{ha}^{-1}$, with the application of $675 \mathrm{~mm}$ of water and $199.1 \mathrm{~kg} \mathrm{ha}^{-1}$ of nitrogen. Already the maximum estimated net income $(R \$ 4,247.60)$ was obtained with productivity level of $28,517.50 \mathrm{~kg} \mathrm{ha}^{-1}$ using $597.1 \mathrm{~mm}$ of water and $198.3 \mathrm{~kg} \mathrm{ha}^{-1}$ of nitrogen.
\end{abstract}

Additional keywords: Cucumis melo L.; evapotranspiration; localized irrigation. 


\section{Introdução}

O meloeiro (Cucumis melo L.) é uma das espécies oleráceas de maior consumo no mundo, e dentre as frutas e hortaliças é a oitava cultura mais produzida mundialmente, com área cultivada de aproximadamente 1,33 milhão de hectares, o que resulta na produção de 31,92 milhões de toneladas no ano de 2012, sendo a China o maior produtor, respondendo por aproximadamente $54,8 \%$ da produção mundial (FAO, 2013).

No Brasil, a área cultivada com melão, no ano de 2012, foi de 22.810 hectares, com a produtividade média de $21.310 \mathrm{~kg} \mathrm{ha}^{-1}$, sendo que a região Nordeste contribuiu com $87,1 \%$ da área plantada no País, o que corresponde a 16.308 hectares plantados.Dentre os estados brasileiros, o Rio Grande do Norte tem a liderança em área plantada e produção, tendo produzido, em 2008, 45,3\% da produção nacional, seguindo em ordem decrescente, pelos Estados do Ceará e Bahia. O Estado do Piauí responde por cerca de $2,5 \%$ da produção nacional (IBGE, 2013).

A região norte do Estado do Piauí, onde se localiza o município de Teresina, mostra boas condições edafoclimáticas e água disponível, sendo que, para uma boa produtividade do meloeiro, são necessárias altas temperaturas, luminosidade, disponibilidade hídrica para irrigação e solos profundos. Estas características podem promover 0 rápido crescimento das áreas ocupadas com esta cultura no Estado, aumentando o nível de oferta de frutas frescas de qualidade, tanto para consumo interno quanto para exportação. Para isto, é indispensável a pesquisa e o desenvolvimento de novas tecnologias que possam melhorar o atual sistema de produção do meloeiro, principalmente quanto ao uso adequado da água e dos nutrientes no solo, de forma a aumentar o rendimento e reduzir o custo de produção.

Os manejos da irrigação e a fertilidade do solo geralmente são feitos para atender plenamente à demanda das plantas, com a finalidade da maximização da produção. Entretanto, estudos têm demonstrado que o manejo deve contribuir para o máximo rendimento econômico e não para a máxima produtividade da cultura (Blanco et al., 2011). Portanto, satisfazer inteiramente às necessidades hídricas e nutricionais das culturas não é suficiente para se obter maior retorno econômico, sendo necessário que se observem tais índices, de forma a minimizar custos e otimizar o rendimento, que são influenciados por tais fatores, assim o fornecimento adequado de água e nutrientes é imprescindível.

Diversos trabalhos foram realizados para se determinar as melhores doses de fertilizantes e lâminas de água na região Nordeste do Brasil para a produção do meloeiro, principalmente nos Estados do Ceará e Rio Grande do Norte (Barros et al., 2002; Monteiro et al., 2008). Já para o Estado do Piauí, ainda são poucas as informações técnicas e científicas da correta quantidade de água e de adubação nitrogenada para a cultura do melão que, por sua vez, representem melhor retorno econômico. Assim, o presente trabalho teve por objetivo avaliar a resposta do melão à aplicação de lâminas de água e de adubação nitrogenada nas condições edafoclimáticas de Teresina, Piauí.

\section{Material e métodos}

O experimento foi conduzido de agosto a novembro de 2010, na área experimental do Centro de Ciências Agrárias da Universidade Federal do Piauí, no município de Teresina-PI (0505'21" $\mathrm{S}$; 4248'07" W e $74 \mathrm{~m}$ de altitude). O clima da região é do tipo Aw', segundo a classificação de Köppen, com médias anuais de temperatura na ordem de 28,6 ${ }^{\circ} \mathrm{C}$, $75 \%$ de umidade relativa do ar e precipitação pluvial média anual de $1.291 \mathrm{~mm}$ (Gomes et al., 2014).

A qualidade da água utilizada para irrigação no meloeiro é classificada como C1S1 (UCCC, 1974), ou seja, não apresentando nenhum tipo de restrição ao uso.

Amostras de solo foram coletadas antes do preparo inicial do ensaio, nas profundidades de 0 0,10 m e 0,10 - 0,20 m e encaminhadas ao laboratório, para as análises químicas e físicas (Tabelas 1 e 2). 0 solo predominante é um Argissolo Vermelho-Amarelo, de textura média, com relevo plano (Embrapa, 2013). A caracterização físico-química foi realizada conforme metodologia apresentada pela Embrapa (1997).

O preparo do solo consistiu em uma aração e duas gradagens. Em seguida, foram abertos sulcos com $35 \mathrm{~m}$ de comprimento e 0,20 m de profundidade, espaçados a $2 \mathrm{~m}$, totalizando vinte e dois sulcos para área útil e dois para a bordadura.

A cultivar de meloeiro utilizada foi a Goldex F1, semeada em bandejas e, após 12 dias da semeadura (DAS), realizou-se o transplante para o solo com duas folhas definitivas, utilizando o espaçamento de 2,0 m entre linhas e 0,25 m entre plantas, equivalendo à população de 20.000 plantas por hectare.

A adubação de base da cultura foi realizada com a aplicação de $200 \mathrm{~kg}$ ha ${ }^{-1}$ de $\mathrm{P}_{2} \mathrm{O}_{5}$ (superfosfato simples - 18\% de $\mathrm{P}_{2} \mathrm{O}_{5}$ ), $300 \mathrm{~kg} \mathrm{ha}^{-1}$ de $\mathrm{K}_{2} \mathrm{O}$ (cloreto de potássio - 58\% de $\mathrm{K}_{2} \mathrm{O}$ ), sendo essa dose dividida em três aplicações: $1 / 3$ aplicada no plantio e as demais aos 20 e 40 dias após o plantio. Já a adubação nitrogenada foi aplicada em função dos tratamentos utilizados $(0 ; 75 ; 150$ e 300 kg ha-1 de N). Cada dosagem foi dividida em cinco aplicações, sendo a primeira realizada no momento do transplante das mudas e as demais a cada dez dias após o transplante (10; 20; 30 e 40 dias). Utilizou-se como fonte de nitrogênio do Sulfato de amônio, na adubação de base, e ureia nas de cobertura. 
Tabela 1 - Características químicas do solo da área experimental.

\begin{tabular}{|c|c|c|c|c|c|c|c|}
\hline \multicolumn{8}{|c|}{ Profundidade $0,00-0,10 \mathrm{~m}$} \\
\hline \multirow{2}{*}{$\begin{array}{c}\mathrm{MO} \\
\left(\mathrm{g} \mathrm{kg}^{-1}\right)\end{array}$} & \multirow{2}{*}{$\begin{array}{l}\mathrm{pH} \\
\mathrm{H}_{2} \mathrm{O}\end{array}$} & $P$ & $\mathrm{~K}$ & $\mathrm{Ca}$ & $\mathrm{Mg}$ & $\mathrm{Na}$ & $\mathrm{Al}$ \\
\hline & & \multicolumn{2}{|c|}{$----\left(\mathrm{mg} \mathrm{dm}{ }^{-3}\right)----$} & \multicolumn{4}{|c|}{---- $\left(\mathrm{cmol}_{\mathrm{c}} \mathrm{dm}^{-3}\right)^{-}$} \\
\hline 6,74 & 6,10 & 8,50 & 54,70 & 2,13 & 0,75 & 0,03 & 0,04 \\
\hline \multicolumn{8}{|c|}{ Profundidade $0,10-0,20 \mathrm{~m}$} \\
\hline 2,63 & 6,00 & 10,00 & 39,00 & 1,71 & 0,49 & 0,03 & 0,00 \\
\hline
\end{tabular}

Tabela 2 - Características físicas do solo da área experimental.

\begin{tabular}{|c|c|c|c|c|c|c|c|}
\hline \multicolumn{8}{|c|}{ Profundidade $0,00-0,10 \mathrm{~m}$} \\
\hline \multicolumn{4}{|c|}{ Composição Granulométrica (\%) } & \multirow[b]{2}{*}{$\begin{array}{l}\text { Classe } \\
\text { Textural }\end{array}$} & \multirow{2}{*}{$\begin{array}{l}\text { Densidade do solo } \\
\left(\mathrm{kg} \mathrm{m}^{-3}\right)\end{array}$} & \multirow{2}{*}{$\begin{array}{c}\text { C.C } \\
(\% \text { massa) }\end{array}$} & \multirow[b]{2}{*}{$\begin{array}{c}\text { P.M.P } \\
\text { (\%massa) }\end{array}$} \\
\hline $\begin{array}{l}\text { Areia } \\
\text { grossa }\end{array}$ & $\begin{array}{l}\text { Areia } \\
\text { Fina }\end{array}$ & Silte & Argila & & & & \\
\hline 57,00 & 28,95 & 6,45 & 7,60 & Areia franca & 1400 & 14,50 & 2,60 \\
\hline \multicolumn{8}{|c|}{ Profundidade $0,10-0,20 \mathrm{~m}$} \\
\hline 66,45 & 19,15 & 4,80 & 9,60 & Areia franca & 1630 & 16,00 & 3,00 \\
\hline
\end{tabular}

C.C - capacidade de campo; P.M.P - ponto de murchamento permanente.

O sistema de irrigação utilizado foi por gotejamento, com uma linha lateral por fileira de plantas. O sistema era composto de 22 linhas laterais de polietileno de $35,0 \mathrm{~m}$ de comprimento e diâmetro nominal de $16 \mathrm{~mm}$. No início de cada linha lateral, foi colocado um registro, para controle das lâminas de água aplicadas nas parcelas, de acordo com os tratamentos. Utilizou-se de tubos gotejadores autocompensantes, com emissores espaçados de $0,3 \mathrm{~m}$ e vazão nominal de $2,21 \mathrm{~L} \mathrm{~h}^{-1}$, à pressão nominal de operação de $200 \mathrm{kPa}$.

A frequência de irrigação foi diária, sendo estabelecida de acordo com os tratamentos, baseados na evapotranspiração da cultura - ETc (L1: 124,8 mm; L2: 249,5 mm; L3: 356,4 mm; L4: 534,6 mm e L5: $712,9 \mathrm{~mm}$ ). A ETo foi calculada com base no método de Penman-Monteith, utilizando o programa CROPWAT 8.0 (FAO, 2009), com os dados diários da Estação meteorológica automática do INMET de Teresina-PI. Os coeficientes de cultivo $(\mathrm{Kc})$ para cada fase fenológica da cultura foram 0,$70 ; 1,21$ e 0,98 , conforme Miranda et al. (1999). Durante o período de aclimatação das mudas, com duração de oito dias após o transplantio, foram aplicadas, em todas as parcelas, lâminas de água correspondentes àETc diária da cultura.

A diferenciação das lâminas de água iniciouse no nono dia após o transplantio (DAT), permanecendo até o 55o DAT, quando foi suspensa a irrigação do experimento, de acordo com Campelo et al. (2014). A primeira colheita iniciou-se aos 62 DAT, e a segunda, aos 68 DAT. Os frutos foram colhidos e armazenados em sala refrigerada, onde se procedeu à pesagem um dia após a colheita.

O delineamento estatístico foi o de blocos ao acaso, com parcelas subdivididas e quatro blocos, sendo que as parcelas tinham cinco níveis de irrigação (L1, L2, L3, L4 e L5), correspondendo a
0,$35 ; 0,7 ; 1,0 ; 1,5$ e 2,0 vezes a ETc, respectivamente, e as subparcelas continham quatro doses de nitrogênio (N0, N1, N2 e N3), correspondentes a 0; 75; 150 e $300 \mathrm{~kg} \mathrm{ha}^{-1}$ de $\mathrm{N}$, respectivamente.

Foram avaliados o rendimento do meloeiro em função das lâminas de água e doses de nitrogênio, e a taxa marginal de substituição de água por nitrogênio (TMS $L N)$. Em que: TMS $\perp N$ indica a taxa em que o consumidor está disposto a trocar determinado produto por outro de forma a manter o mesmo nível de utilidade. Desta forma, a TMS do fator lâmina de irrigação pelo fator dose de nitrogênio corresponde à quantidade do fator água que se dispõe a abandonar uma unidade a mais do fator nitrogênio, mantendo-se o mesmo nível de rendimento. A mesma foi obtida pela relação entre o produto físico marginal do nitrogênio e o produto físico marginal da água, e é representada pela equação (1). Por sua vez, o produto físico marginal é obtido por meio da derivada primeira da função que representa o rendimento, em relação ao fator considerado, sendo representado pela equação geral (equação 2).

$$
\mathrm{TMS}_{\mathrm{L} / \mathrm{N}}=\frac{\mathrm{PMgN}}{\mathrm{PMgL}}
$$

Em que: TMS $\perp N$ é a taxa marginal de substituição do fator água $(L)$ pelo fator nitrogênio $(N)$; $P M g N$ é o produto marginal do fator nitrogênio; PMgL é o produto marginal do fator água.

$\operatorname{PMg}(f)=\frac{\partial Y}{\partial f}$

Em que: $P M g(f)$ é o produto físico marginal do fator considerado; $\frac{\partial Y}{\partial f}$ é a derivada da função em relação ao fator considerado.

A estatística dos resultados foi realizada pela análise de variância e teste $\mathrm{F}$. $\mathrm{O}$ efeito das 
lâminas de água e das doses de $\mathrm{N}$ foi analisado pelo teste de regressão polinomial. Neste experimento, os fatores de produção de água $(L)$ e de nitrogênio $(N)$ constituíram-se nas variáveis independentes, e a produtividade da cultura $(\mathrm{Y})$, como variável dependente. Para a obtenção da função de produção, foram testados dez modelos estatísticos que, de acordo com Hexem\&Heady(1978) e Soares et al. (2002), representam satisfatoriamente uma função de produção da cultura. Dentre estes modelos, foi escolhido aquele que melhor se ajustou aos dados do experimento, tendo em vista os coeficientes de determinação $r^{2}$ e $r^{2}$ ajustados, o valor do teste $\mathrm{F}$ da análise de variância, os valores do teste $\mathrm{t}$ para todos os coeficientes e os sinais das variáveis dos modelos analisados. Os modelos estatísticos testados são apresentados nas Equações de 3 a 12.

$$
\begin{aligned}
& \hat{Y}=b_{0}+b_{1} L+b_{2} N+b_{3} L^{0,5}+b_{4} N^{0,5}+b_{5} L^{0,5} N^{0,5}+e i \\
& \hat{Y}=b_{0}+b_{1} L+b_{2} N+b_{3} L^{0,5}+b_{4} N^{0,5}+b_{5} L N+e i \\
& \hat{Y}=b_{0}+b_{1} L+b_{2} N+b_{3} L^{0,5}+b_{4} N^{0,5}+e i \\
& \hat{Y}=b_{0}+b_{1} L+b_{2} N+b_{3} L^{2}+b_{4} N^{2}+b_{5} L N+e \\
& \hat{Y}=b_{0}+b_{1} L+b_{2} N+b_{3} L^{2}+b_{4} N^{2}+e i \\
& \hat{Y}=b_{0}+b_{1} L+b_{2} N+b_{3} L^{1,5}-b_{4} N^{1,5}+b_{5} L N+e i \\
& \hat{Y}=b_{0}+b_{1} L+b_{2} N-b_{3} L^{1,5}-b_{4} N^{1,5}+e i \\
& \hat{Y}=b_{0}+b_{1} L-b_{2} L^{2}-b_{3} N^{2}+e i \\
& \hat{Y}=b_{1} L+b_{2} N-b_{3} L^{2}-b_{4} N^{2}+b_{5} L N+e i \\
& \hat{Y}=b_{1} L+b_{2} N-b_{3} L^{2}-b_{4} N^{2}+e i
\end{aligned}
$$

Em que: $\hat{Y}$ é a produtividade estimada da cultura do meloeiro $\left(\mathrm{kg} \mathrm{ha}^{-1}\right)$; $\mathrm{L}$ é o fator água $(\mathrm{mm})$; $\mathrm{N}$ é o fator nitrogênio $\left(\mathrm{kg} \mathrm{ha}^{-1}\right)$.

\section{Resultados e discussão}

Observou-se que as lâminas de água e as doses de $\mathrm{N}$ influenciaram significativamente sobre a produtividade do melão, aos níveis de $0,17 \%$ e $0,001 \%$, respectivamente (Tabela 3 ), mostrando que o nitrogênio foi o fator que mais influenciou no rendimento do melão. Portanto, o meloeiro é uma cultura responsiva a níveis crescentes de água e de adubação nitrogenada; assim, apresentando incremento na produtividade, pois a água interfere nas características físicas da planta, e o nitrogênio, nos aspectos de qualidade do fruto. Porém, a interação entre os dois fatores, água e $\mathrm{N}$, não apresentou significância ao nível de 5\%. Desta forma, a probabilidade de erro ao se afirmar que as interações entre os dois fatores influenciaram no rendimento da cultura é de 66,67\%. De acordo com Mousinho et al. (2003), a falta de interação entre água e nitrogênio supõe a independência dos mesmos, podendo acontecer devido à influência de outros fatores sobre a utilização do $\mathrm{N}$ pelas culturas, como $\mathrm{pH}$ e teor de cálcio no solo, bem como as características físicas do solo, que podem influenciar na retenção e na disponibilidade para a cultura.

Melo et al. (2011), trabalhando com a cultura do melão, obtiveram resultados similares aos encontrados, com relação aos fatores água salina e nitrogênio, analisados isoladamente, e os mesmos verificaram que tanto a água quanto o nitrogênio influenciaram significativamente no rendimento das culturas, sem haver interação significativa entre os dois fatores. Já Freitas et al. (2014), trabalhando com a produção do meloeiro cultivado sob diferentes níveis de salinidade e nitrogênio, verificaram que somente as lâminas de água salina influenciaram no rendimento da cultura.

Tabela 3 - Resumo da análise de variância do rendimento do meloeiro em função das lâminas de água e das doses de nitrogênio.

\begin{tabular}{lcccc}
\hline Fontes de variação & Grau de liberdade & Soma de quadrados & Quadrado médio & Prob. > F \\
\hline Blocos & 3 & 66872992 & 22290997 & \\
Água $(\mathrm{L})$ & 4 & 1,8154266 & 453856664 & 0,0017 \\
Resíduo A & 12 & 636170999 & 53014249 & \\
\hline Parcelas & 19 & 25561 & & \\
\hline Nitrogênio (N) & 3 & 933615988 & 311205329 & 0,00001 \\
Interação L x N & 12 & 302231622 & 25185968 & 0,6667 \\
Resíduo B & 45 & 1,4515778 & 32257286 & \\
\hline TOTAL & 79 & 5,20589618 & & \\
\hline
\end{tabular}

Verificou-se, pela análise de regressão, que todos os dez modelos testados (Equações 3 a 12) foram significativos pelo teste $\mathrm{F}$, a $1 \%$, evidenciando que todos os modelos podem representar a variação da produtividade do melão $(\mathrm{Y})$ em função das doses de nitrogênio $(N)$ e das lâminas de água $(L)$, nas condições estudadas. No entanto, observou-se que o modelo que melhor se ajustou aos dados do 
experimento foi o da Equação 12, sendo este polinomial quadrático, sem intercepto e sem interação significativa entre os fatores lâmina de água e doses de N, conforme a Equação 13:

$$
\begin{aligned}
\hat{Y}= & 52,40174118 L+111,1536525 N-0,038815548 L^{2}- \\
& -0,279112997 N^{2}
\end{aligned}
$$

Para o modelo escolhido, o coeficiente de determinação $\left(r^{2}\right)$ foi de 0,695 , significando que o rendimento do meloeiro pode ser explicado pela variação das lâminas de água e pelas doses de nitrogênio. Na Figura 1, visualiza-se a função de produção estimada. Observa-se que o fator nitrogênio influencia mais sobre o rendimento da cultura do que o fator água. Isso é evidenciado pela maior curvatura da linha do fator nitrogênio na superfície de resposta. Monteiro et al. (2006), trabalhando com melão no Vale do Curu-CE, também observaram maior influência deste fator no rendimento da cultura.

O máximo rendimento estimado para 0 meloeiro foi de $28.752,3 \mathrm{~kg} \mathrm{ha}^{-1}$, obtido com a aplicação de lâmina de água de $675 \mathrm{~mm}$ e 199,1 kg ha-1 de N. Soares et al. (2013), analisando a cultura do meloeiro, obtiveram máximo rendimento físico de $34.258,4 \mathrm{~kg} \mathrm{ha}^{-1}$ com aplicação de $179,44 \mathrm{~kg} \mathrm{ha}^{-1}$ de $\mathrm{N}$ e lâmina de 534,64 mm. Já Gomes et al. (2011) observaram que a lâmina de água econômica e a respectiva produção para o meloeiro foram de $673,85 \mathrm{~mm}$, proporcionando rendimento de $29.706,6 \mathrm{~kg} \mathrm{ha}^{-1}$.
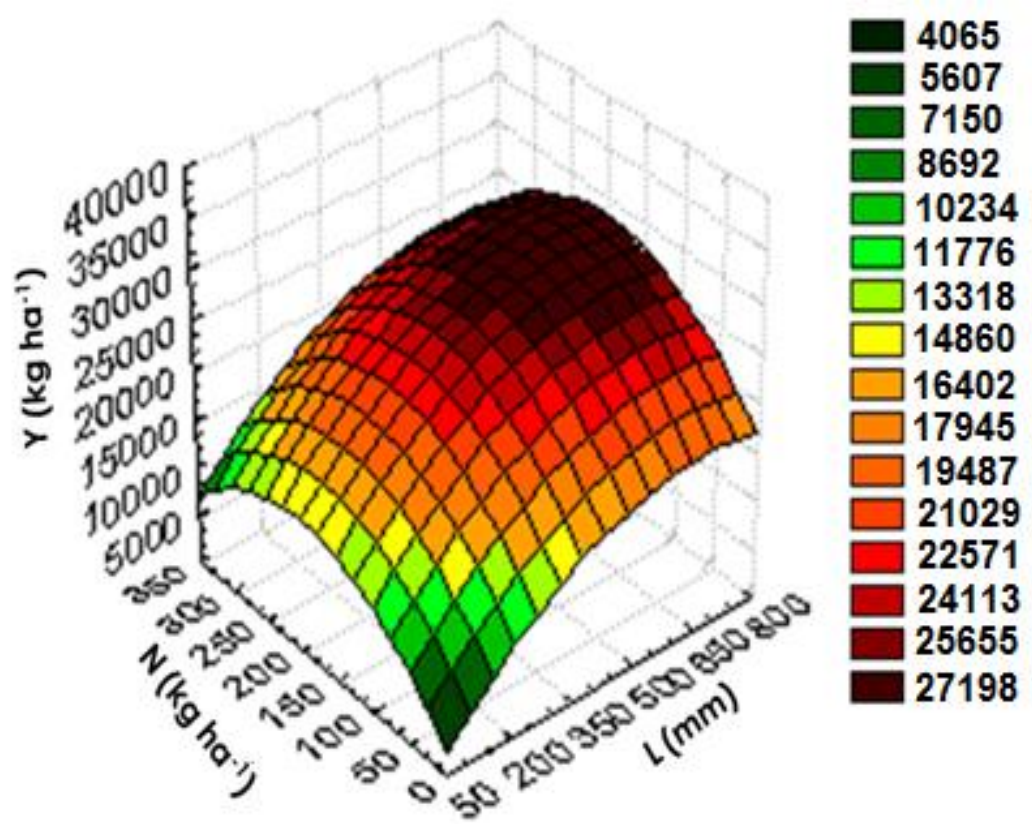

Figura 1 - Superfície de resposta do rendimento do melão (Y) em função das lâminas de água (L) e das doses de nitrogênio $(\mathrm{N})$.

$\mathrm{Na}$ Figura 2, visualizam-se as isoquantas, curvas de isoprodutos, que foram obtidas a partir da função de produção. As isoquantas evidenciam as combinações entre as doses de $\mathrm{N}$ e as lâminas de água, que resultam no mesmo rendimento. Tais combinações evidenciam que quanto maior 0 rendimento, menor a quantidade de combinações, até o ponto que se obtém uma única combinação, que corresponde ao máximo rendimento físico, neste caso de $28.752,3 \mathrm{~kg} \mathrm{ha}{ }^{-1}$. As curvas de isoprodutos preceituam a substituição de fatores, em que um fator pode substituir outro sem que haja alteração no produto.

Para demonstrar tal conceito, pode-se observar que o rendimento de $15.631,4 \mathrm{~kg} \mathrm{ha}^{-1}$ de melão pode ser obtido, dentre outras combinações, com aplicação de $19,4 \mathrm{~kg} \mathrm{ha}^{-1}$ de $\mathrm{N}$ e $350 \mathrm{~mm}$ de água ou com $74 \mathrm{~kg} \mathrm{ha}^{-1}$ de $\mathrm{N}$ e $200 \mathrm{~mm}$ de água e um rendimento de $25.460 \mathrm{~kg} \mathrm{ha}^{-1}$; da mesma forma, pode ser obtido com $75,5 \mathrm{~kg} \mathrm{ha}^{-1}$ de $\mathrm{N}$ e $650 \mathrm{~mm}$ de água ou com $118,5 \mathrm{~kg} \mathrm{ha}^{-1}$ de $\mathrm{N}$ e $480 \mathrm{~mm}$ de água. Verifica-se também uma redução gradativa nas curvas dos isoprodutos à medida que o rendimento aumenta. Isso se explica devido aos menores acréscimos de rendimento à medida que se incrementa o uso dos fatores de produção, segundo Leftwich (1976), se deve ao fato de que, embora haja certo grau de substituição entre os fatores água e $\mathrm{N}$, estes não são substitutos perfeitos. 

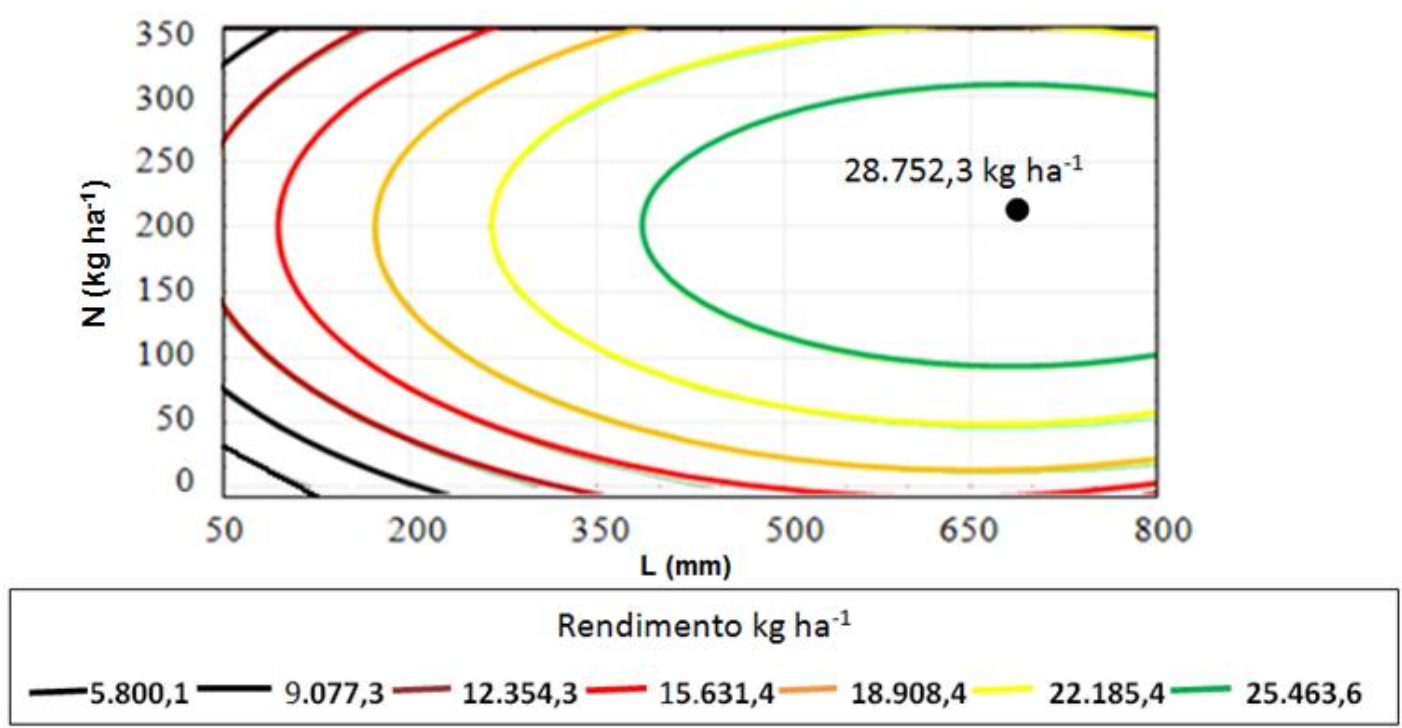

Figura 2 - Curvas de isoprodutos para o rendimento do melão $\left(\mathrm{kg} \mathrm{ha}^{-1}\right)$ em função das lâminas de água (L) e das doses de nitrogênio $(\mathrm{N})$.

Os valores da taxa marginal de substituição (TMS) da água por nitrogênio estão dispostos na Tabela 4. Observando-se esses valores obtidos para níveis de produção preestabelecidos, em que inicialmente a TMS é negativa, indica-se que a substituição da água por $\mathrm{N}$ pode ser economicamente viável e é substituída em proporções decrescentes. No momento em que a mesma se torna positiva, a substituição passa a ser não econômica, indicando que a água está sendo substituída por $\mathrm{N}$ em proporções crescentes. Pode-se comprovar que as TMSs para os rendimentos são crescentes, ou seja, à medida que se elevam os rendimentos, as doses de $\mathrm{N}$, que proporcionam a viabilidade econômica, tendem a aumentar. Para os rendimentos de 16.000 e 19.000 $\mathrm{kg} \mathrm{ha}^{-1}$, a viabilidade inicia-se com a dose de $15 \mathrm{~kg}$ $\mathrm{ha}^{-1}$ de $\mathrm{N}$.

Tabela 4 - Taxa marginal de substituição de água por nitrogênio (TMS $L / N)$ e as correspondentes lâminas de água $(\mathrm{L})$ e doses de nitrogênio $(\mathrm{N})$ para níveis predeterminados de rendimento.

\begin{tabular}{ccccccccccc}
\hline \multirow{2}{*}{$N$} & \multicolumn{7}{c}{ Rendimentos $\left(\mathrm{kg} \mathrm{ha}^{-1}\right)$} \\
\cline { 2 - 12 }$\left(\mathrm{kg} \mathrm{ha}^{-1}\right)$ & $\mathrm{L}(\mathrm{mm})$ & TMS & $\mathrm{L}(\mathrm{mm})$ & TMS & $\mathrm{L}(\mathrm{mm})$ & TMS & $\mathrm{L}(\mathrm{mm})$ & TMS & $\mathrm{L}(\mathrm{mm})$ & TMS \\
0 & 466,61 & $-6,87$ & - & - & - & - & - & - & - & - \\
15 & 383,86 & $-4,55$ & 588,52 & $-15,31$ & - & - & - & - & - & - \\
30 & 324,48 & $-3,47$ & 461,51 & $-5,70$ & - & - & - & - & - & - \\
45 & 277,85 & $-2,79$ & 391,38 & $-3,91$ & 618,82 & $-19,72$ & - & - & - & - \\
60 & 239,85 & $-2,3$ & 340,23 & $-2,99$ & 488,50 & $-5,36$ & - & - & - & - \\
75 & 208,37 & $-1,91$ & 300,22 & $-2,38$ & 423,65 & $-3,55$ & - & - & - & - \\
90 & 182,15 & $-1,59$ & 268,04 & $-1,93$ & 377,79 & $-2,64$ & 569,90 & $-7,46$ & - & - \\
105 & 160,39 & $-1,32$ & 241,94 & $-1,56$ & 342,96 & $-2,04$ & 493,43 & $-3,73$ & - & - \\
120 & 142,54 & $-1,07$ & 220,88 & $-1,25$ & 315,92 & $-1,58$ & 447,73 & $-2,50$ & - & - \\
135 & 128,23 & $-0,84$ & 204,18 & $-0,98$ & 295,02 & $-1,21$ & 415,96 & $-1,78$ & - & - \\
150 & 117,17 & $-0,63$ & 191,38 & $-0,73$ & 279,27 & $-0,89$ & 393,37 & $-1,25$ & 629,94 & $-7,84$ \\
165 & 109,18 & $-0,43$ & 182,19 & $-0,50$ & 268,09 & $-0,60$ & 377,86 & $-0,83$ & 570,08 & $-2,34$ \\
180 & 104,13 & $-0,24$ & 176,39 & $-0,28$ & 261,09 & $-0,33$ & 368,35 & $-0,45$ & 545,58 & $-1,06$ \\
195 & 101,94 & $-0,05$ & 173,89 & $-0,06$ & 258,07 & $-0,07$ & 364,29 & $-0,10$ & 536,23 & $-0,21$ \\
\hline
\end{tabular}


No nível de rendimento de $28.000 \mathrm{~kg} \mathrm{ha}^{-1} \mathrm{de}$ melão, só se obtiveram as TMS, para as doses de $\mathrm{N}$ maiores ou iguais a $150 \mathrm{~kg} \mathrm{ha}^{-1}$. Para o rendimento de $25.000 \mathrm{~kg} \mathrm{ha}^{-1}$ de melão, só a partir da dose de $90 \mathrm{~kg}$ $\mathrm{ha}^{-1}$ de $\mathrm{N}$, obteve-se este nível de produção, em que seria necessário empregar $7,6 \mathrm{~mm}$ de água para substituir um quilograma de $\mathrm{N}$, de modo a manter o mesmo nível de produção. Isto significa que, para cada $\mathrm{kg}$ de $\mathrm{N}$ aplicado, pode-se economizar 7,6 mm de água. Para a dose de $150 \mathrm{~kg} \mathrm{ha}^{-1} \mathrm{de} \mathrm{N}$, a economia seria apenas de 1,25 $\mathrm{mm}$ para cada $\mathrm{kg}$ aplicado. Já para as doses de N, em que a TMS se tornou positiva, evidencia-se que, em vez de se economizar água, passa-se a gastar mais água a cada $\mathrm{kg}$ de $\mathrm{N}$ aplicado, tornando a atividade não econômica.

As TMSs obtidas para 0 presente trabalho corroboram os obtidos por Mousinho et al. (2003) e Monteiro et al. (2006), em trabalhos com melancia e melão, respectivamente, em que os mesmos obtiveram TMS, inicialmente negativas e decrescentes.

A substituição de um fator por outro só tem vantagem econômica se a taxa marginal de substituição em valor absoluto for superior à relação inversa entre os preços dos fatores. Desta forma, só seria vantajosa a substituição da água por $\mathrm{N}$, neste estudo, quando o valor absoluto da taxa marginal de substituição for maior que 11,8 . Assim, para o presente trabalho, tal fato só aconteceria para os níveis de rendimento de 19.000 e $22.000 \mathrm{~kg} \mathrm{ha}^{-1}$ de melão, para as doses de 15 e $45 \mathrm{~kg} \mathrm{ha}^{-1}$ de $\mathrm{N}$, respectivamente.

A região de produção racional de melão é caracterizada pelas diferentes combinações entre os fatores, para os respectivos rendimentos, em que a atividade é economicamente desejável. Esta região é delimitada por linhas denominadas linhas de fronteiras que, entre outras coisas, mostram as quantidades mínimas de $\mathrm{L}$ e $\mathrm{N}$ para produzir quantidades distintas de melão. Essas linhas de fronteiras ligam os pontos em que a curva dos isoprodutos são verticais e horizontais, ou seja, ligam pontos onde a TMS é infinita ou zero. Dentro da região de produção racional, as TMSs são sempre negativas, indicando que os fatores são substitutos técnicos um do outro, ou seja, quando se usar uma quantidade menor de $\mathrm{N}$, deve-se usar maior quantidade de $\mathrm{L}$ para que $\mathrm{o}$ produto permaneça constante (Soares et al., 2002).

$\mathrm{Na}$ região de produção racional do meloeiro (Figura 3), não houve a interação entre os fatores água e nitrogênio, para os níveis de rendimento estabelecidos, e observa-se que as lâminas de água e as doses de $\mathrm{N}$ que delimitam a região de produção racional foram iguais. Desta forma, os valores de lâmina de água e de dose de $\mathrm{N}$ que demarcam a região de produção racional, são delimitados pelas linhas LO e NO, respectivamente.
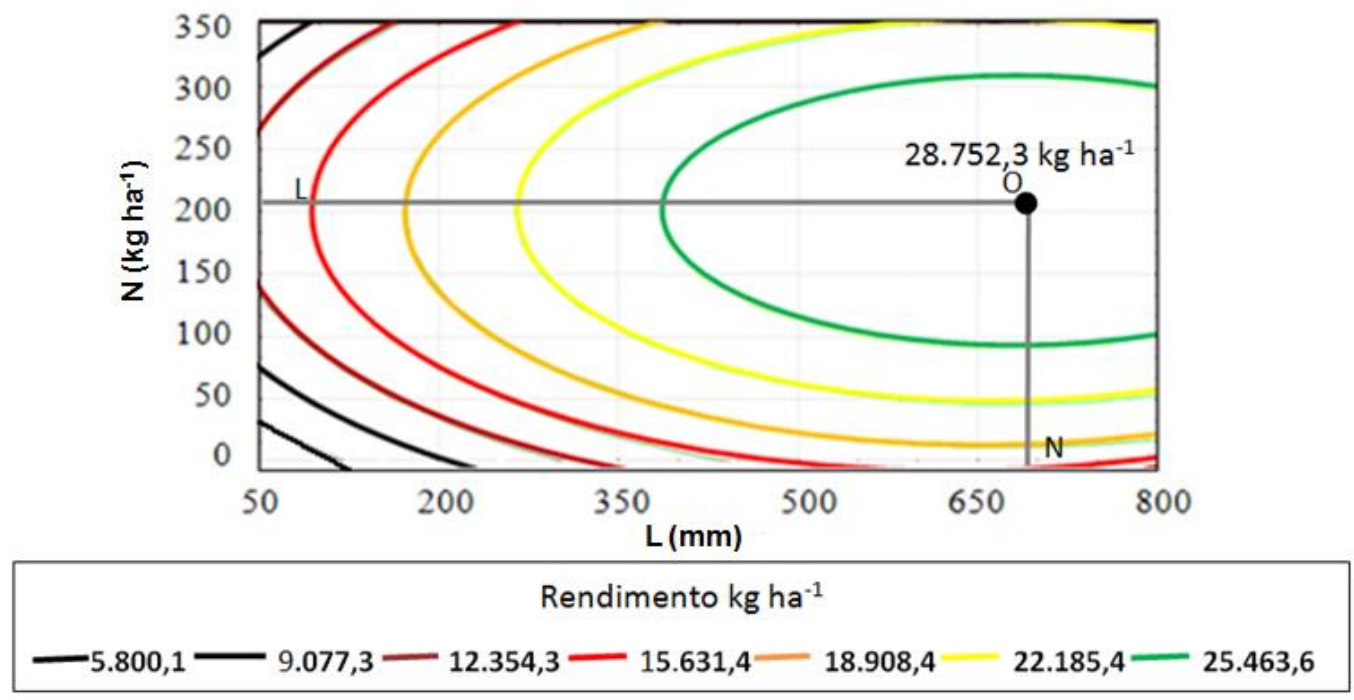

Figura 3 - Região de produção racional do melão em função das lâminas de água e das doses de nitrogênio.

Considerando não haver restrição de capital para a aquisição dos fatores água e $\mathrm{N}$ que conduziram a máxima receita líquida, as quantidades dos fatores foram obtidas ao se igualar o produto marginal da água com a relação entre o preço da água e o preço do melão $\left(\mathrm{P}_{\llcorner} / \mathrm{PY}\right)$, e o produto marginal do $\mathrm{N}$ com a relação entre o preço do nitrogênio e o preço do melão $\left(\mathrm{P}_{\mathrm{N}} / \mathrm{P}_{\mathrm{Y}}\right)$, respectivamente, conforme as equações a seguir:

$$
\begin{aligned}
& P M g N=111,1537-0,55823 N=\frac{P N}{P Y} \\
& P M g L=52,40174-0,07763 L=\frac{P L}{P Y}
\end{aligned}
$$

Observa-se que, para o mês de novembro de 2011, o preço da água foi considerado como igual ao valor da tarifa de energia elétrica, conforme sugere Frizzone et al. (1993). Em que o valor da água foi de $\mathrm{R} \& 0,318 \mathrm{~mm}^{-1} \mathrm{ha}^{-1}$, fornecido pela Empresa de 
Águas e Esgotos do Piauí SA (AGESPISA, 2011), o do $\mathrm{N}$ de $\mathrm{R} \$ 3,50 \mathrm{~kg}^{-1} \mathrm{com}$ base em pesquisas locais, e o do melão, $R \$ 0,58 \mathrm{~kg}^{-1}$, de acordo com dados da Central de abastecimento de Teresina - Ceapi.

As quantidades de água e $\mathrm{N}$ para se obter a máxima receita líquida foram, respectivamente, $597,1 \mathrm{~mm}$ e $198,3 \mathrm{~kg} \mathrm{ha}^{-1}$. Substituindo os referidos valores na função de produção, tem-se que a máxima receita líquida seria obtida com rendimento de $28.517,5 \mathrm{~kg} \mathrm{ha}^{-1}$ de melão. Tendo em vista o custo de produção da cultura ( $R \$ 10.440,00$ por hectare), os custos fixos ( $R \$ 969,50$ por hectare), estimados pela equação 15 e os custos com água e $\mathrm{N}$, que para a maximização da receita líquida seriam de $R \$$ 883,40 , a máxima receita líquida obtida para este rendimento seria de $R \$ 4.247,60$ por hectare.

Caso haja restrição de capital para a aquisição de água e $N$, e dispondo-se de apenas $R \$$ 600,00 para se gastar com os referidos fatores, a máxima receita líquida seria de $\mathrm{R} \$ 2.387,6$ por hectare, sendo que, para a obtenção desta receita, seria necessário aplicar uma lâmina de água de $408,3 \mathrm{~mm}$ e dose de $\mathrm{N}$ de $134,4 \mathrm{~kg} \mathrm{ha}^{-1}$, obtendo um rendimento de $33.612,69 \mathrm{~kg} \mathrm{ha}^{-1}$ de melão.

\section{Conclusões}

A análise conjunta dos fatores de produção, água e nitrogênio, mostra efeito significativo sobre o rendimento do melão, não apresentando interação significativa entre estes fatores.

O rendimento máximo estimado do meloeiro é $28.752,3 \mathrm{~kg} \mathrm{ha}^{-1}$, a ser obtido com lâmina de água e com dose de $\mathrm{N}$ de $675 \mathrm{~mm}$ e $199,1 \mathrm{~kg} \mathrm{ha}^{-1}$, respectivamente. Já a máxima receita líquida estimada ( $R \$ 4.247,60)$ é obtida com nível de rendimento de $28.517,50 \mathrm{~kg} \mathrm{ha}^{-1}$, aplicando $597,1 \mathrm{~mm}$ de água e $198,3 \mathrm{~kg} \mathrm{ha}^{-1}$ de $\mathrm{N}$.

\section{Referências}

AGESPISA - Empresa de Abastecimento de Água e Saneamento Básico do Estado Brasileiro do Piauí (2011). Disponível em < http://www.AGESPISA.com.br>. Acesso em 12 de nov. 2011.

Barros VS, Costa RNT, Aguiar VA (2002) Função de produção da cultura do melão para níveis de água e adubação nitrogenada no vale de Curu-CE. Irriga,7:98105.

Blanco FF, Cardoso MJ, Freire Filho FR, Veloso MEC, Nogueira CCP, Dias NS (2011) Milho verde e feijão-caupi em consórcio sob diferentes lâminas de irrigação e doses de fósforo. Pesquisa Agropecuária Brasileira 46:524-530.

Campelo AR, Azevedo BM, Nascimento Neto JR, Viana TV, Neto LGP, Lima RH (2014) Manejo da cultura do melão submetida a frequências de irrigação e fertirrigação com nitrogênio. Horticultura Brasileira, 32(2):138-144.
Embrapa (1997) Empresa Brasileira de Pesquisa Agropecuária. Manual de métodos de análises de solo. Ministério da Agricultura e do Abastecimento, Rio de Janeiro. 212p.

Embrapa (2013) Empresa Brasileira de Pesquisa Agropecuária. Sistema brasileiro de classificação de solos. 3. ed. Embrapa Solos, Brasília. 353p.

FAO - Food and Agriculture Organization of the United Nations (2013). Disponível em <http://www.faostat.fao.org/site/567/default.spx\#ancor/>. (Acessoem16 ago. 2014).

FAO - Food and Agriculture Organization of the United Nations (2009). Cropwat 8.0 for Windows userguide. Rome, Italy. Disponível em <www.fao.org>. (Acesso em 10 ago. 2014).

Freitas LDA, Figueiredo VB, Porto Filho FQ, Costa JC, Cunha EM (2014) Crescimento e produção do meloeiro cultivado sob diferentes níveis de salinidade e nitrogênio. Revista Brasileira de Engenharia Agrícola e Ambiental, 18:20-26.

Frizzone JA (1993) Funções de resposta das culturas à irrigação. Piracicaba, ESALQ/USP, (Série Didática, 6), 42p.

Gomes ER, Silva LRA, Andrade Júnior AS, Sousa VF, Mousinho FEP (2014) Potencial hídrico foliar da melancieira em resposta a variação no conteúdo de água no solo. Irriga, 1:29-39.

Gomes ER, Rocha Júnior AF, Soares CA, Mousinho FEP, Salviano AAC (2011) Função de resposta do meloeiro à aplicação de lâminas de água para as condições edafoclimáticas de Teresina-PI. In: Congresso nacional de irrigação e drenagem. Anais, Petrolina, 6p.

Hexem RW, Heady EO (1978) Water production functions for irrigated agriculture. The lowa University Press, Ames, 215p.

IBGE - Instituto Brasileiro de Geografia e Estatística (2013). Disponível em <http://www.sidra.ibge.gov.br $\geq$. Acesso em 16 de ago. 2014.

Leftwich PH (1976) O sistema de preços e a alocação de recursos. Pioneira, São Paulo, 399p.

Melo TK, Medeiros JF, Espínola Sobrinho J, Figueirêdo VB, Pereira VC, Campos MS (2011) Evapotranspiração e produção do melão Gália irrigado com água de diferentes salinidades e adubação nitrogenada. Revista Brasileira de Engenharia Agrícola e Ambiental, 15:1235-1241. 
Miranda FR, Souza F, Ribeiro RSF (1999) Estimativa da evapotranspiração e do coeficiente de cultivo para a cultura do melão plantado na região litorânea do Estado do Ceará. Engenharia Agrícola,18(4):63-70.

Monteiro ROC, Colares DS, Costa RNT, Leão MCS, Aguiar JVA (2006) Função de resposta do meloeiro a diferentes lâminas de irrigação e doses de nitrogênio. Horticultura Brasileira, 24:455-459.

Monteiro ROC, Costa RNT, Leão MCS, Aguirar JV (2008) Eficiência do uso da água e nitrogênio na produção de melão. Irriga, 13:367-377.

Mousinho FEP, Costa RNT, Souza F, Gomes Filho R (2003) Função de resposta da melancia à aplicação de água e adubo nitrogenado para as condições edafoclimáticas de Fortaleza. Irriga, 8:264-272.
Soares JI, Costa RNT, Silva LAC, Gondim RS (2002) Função de resposta Função de resposta da melancia aos níveis de água da melancia aos níveis de água e adubação nitrogenada, no Vale do Curu, CE. Revista Brasileira de Engenharia Agrícola e Ambiental, 6(2):219-224.

Soares CA, Rocha Júnior AFR, Silva NS, Mousinho FEP, Zanini JR (2013) Função de resposta do meloeiro a doses de adubação nitrogenada para dois níveis de irrigação. Comunicata Scientiae, 4:391-400.

UCCC - University of California Committee of Consultants (1974) Guidelines for interpretation of water quality for agriculture. University of California, Davis, $13 p$. 